\title{
The influence of space weather on ionospheric total electron content during the 23 rd solar cycle
}

\author{
Nicolas Bergeot ${ }^{1}$,* , Ioanna Tsagouri ${ }^{2}$, Carine Bruyninx ${ }^{1}$, Juliette Legrand ${ }^{1}$, Jean-Marie Chevalier ${ }^{1}$, Pascale Defraigne ${ }^{1}$, \\ Quentin Baire $^{1}$, and Eric Pottiaux ${ }^{1}$ \\ 1 Royal Observatory of Belgium, 3 avenue Circulaire, 1180 Brussels, Belgium \\ *Corresponding author: e-mail: nicolas.bergeot@oma.be \\ 2 Institute for Space Applications and Remote Sensing, National Observatory of Athens, 15236 Mount Penteli, Greece
}

Received 6 March 2013 / Accepted 3 July 2013

\begin{abstract}
This paper presents a new empirical model for predicting the daily mean ionospheric Total Electron Content (TEC) at a given latitude from only one solar index as input. For the development of the model we take advantage of the availability of 15 years of global GNSS-based TEC information and solar indices (Sunspot Number, F10.7 and derived F10.7P) including the 23rd solar cycle. Among all the tests, our preferred ionospheric climatological model to predict daily mean TEC presents yearly median differences with observed values of $1.4 \pm 0.9 \mathrm{TECu}(11.5 \pm 2.9 \%$ for the relative differences) with no significant degradation during the different phases of the solar cycle. To realize this empirical model we used a least-square adjustment with (1) a combination of linear, annual and semi-annual terms between the TEC and F10.7P; (2) a discretization with respect to the phases of the solar cycle. The main differences between the modelled and the observed TEC occur during identified geomagnetic storms: the maximum differences $(-3.2 \pm 1.5 \mathrm{TECu})$ and relative differences $(-19.6 \pm 15.0 \%)$ occur one day after the storm onset. The typical time to retrieve the pre-storm conditions is 3-4 days after the onset. These results show a global picture of the effect of extreme Space Weather events on the Earth's upper atmosphere.
\end{abstract}

Key words. total electron content - ionosphere (general) - modelling - climate - storm

\section{Introduction}

An increasing demand on a better modelling and understanding of the behaviour of the ionosphere-plasmasphere system is required by the scientific community which uses electromagnetic wave signals passing through this system. This is particularly the case for GNSS (Global Navigation Satellite Systems, e.g., GPS, GLONASS, GALILEO ...) were the Total Electron Content (TEC) between the ground receivers and the satellites is one of the main error sources for positioning applications, especially for single frequency users. Consequently, one of the future challenges of the Space Weather community is to predict the Earth's ionospheric-plasmaspheric TEC in response to variations of the solar activity and geomagnetic storm events. Note that in the present paper, we will use for more simplicity the term ionospheric TEC instead of ionospheric-plasmaspheric TEC.

Many studies and models concerning the ionospheric state during quiet and geomagnetic storm periods were based on long-term ionosonde data (e.g., Rishbeth 1998; Tsagouri et al. 2000) for different latitudes and solar activity levels. These studies, which are based on data up to the peak of the F2 layer, describe the variation of the maximum electron density of the F2 layer (NmF2) at different locations, solar activity and geomagnetic conditions. The main conclusion is that the variation of the peak of the electron density is mainly driven by (1) the photo-ionization of the neutral atmosphere by solar extreme ultraviolet (EUV) radiation, (2) the neutral composition i.e., the atomic to molecules ratio (especially $[\mathrm{O}] /\left[\mathrm{N}_{2}\right]$ ) and (3) many secondary phenomena (e.g., neutral waves propagating from below, thermospheric winds, $E \times B$ drift). The relative importance of the driving mechanisms depends strongly on the latitude of the observation point and the level of the geomagnetic activity. One of the remarkable applications of all these studies is the realization and improvement of the empirical International Reference Ionospheric (IRI) model (e.g., Bilitza 2001; Bilitza et al. 2011) which is now widely used in different scientific areas. The IRI model permits, among other things, the reconstruction of the electron density profiles up to plasmaspheric heights and the TEC prediction. However, many studies compared the TEC derived from IRI and GNSS and show systematic bias in the IRI-TEC (e.g., Kenpankho et al. 2011; Orús et al. 2002). These discrepancies are interpreted by the lack of knowledge of the upper part of the ionosphere (e.g., Iwamoto et al. 2002) and lead to a focus on the improvement of the topside ionospheric models in IRI (Bilitza et al. 2006). To address this problem, GNSS technique is becoming a key tool to add information on the ionospheric TEC from $60 \mathrm{~km}$ to 20,000 $\mathrm{km}$ (mean altitude of the satellites) on a global scale. Therefore, the IRI community is planning to incorporate the GNSS-based TEC estimations to address TEC bias (Bilitza et al. 2011). At this stage, the main question is how to incorporate such GNSS-based TEC to constrain ionospheric empirical models.

The beginning of the $23 \mathrm{rd}$ solar cycle coincided with the start of the catalogue of global ionospheric TEC maps based on GNSS data. Consequently, the 23rd solar cycle (19962008) is the first full solar cycle ever having both observed solar 
indices and GNSS-based TEC measurements. Several studies described the climatological patterns of the TEC (e.g., mean daily TEC at a given band of latitude) and determined the linear, annual and semi-annual components of the ionospheric TEC response with respect to solar indices for a complete solar cycle. These studies highlighted, on a global scale, different patterns (linearity, saturation and amplification) of the TEC with respect to solar indices (e.g., Liu \& Chen 2009; Liu et al. 2009). In parallel, an empirical model constrained by long-term GNSS-based data has been proposed (Jakowski et al. 2011) to describe the TEC behaviour in response to solar EUV. The model is in good accordance with the observed TEC $(0.3 \pm 7.5 \mathrm{TECu})$ but there is a systematic non-negligible bias especially in the southern hemisphere (latitude $<-50{ }^{\circ} \mathrm{S}$ ) during high solar activity. Moreover, this model has not been tested during storm conditions.

The present paper aims at establishing the basis to model the climatological behaviours of the TEC on a global scale and to quantify its variations during geomagnetic storms. Our study takes advantage of the new double data set (solar indices and GNSS-based TEC, Sect. 1) during the entire 23rd solar cycle in order (1) to develop an empirical ionospheric climatological model to predict the mean daily TEC at a given latitude taking only one solar index as input and (2) to analyse the variation of the TEC during identified geomagnetic storm events. Our climatological TEC model is based on the quantification and interpretation of linear and nonlinear relations with solar indices (Sect. 2). Then we compare the modelled TEC and GNSS-based TEC for different latitudes (Sect. 3), and finally describe the behaviour of our model during identified geomagnetic storms for the period 1998-2005 (Sect. 4).

\section{Data sets}

\subsection{Ionospheric data}

The Centre for Orbit Determination in Europe (CODE) analysis centre uses ground-based GNSS (Global Navigation Satellite Systems, e.g., GPS, GLONASS, Galileo) observations from more than 250 globally distributed GNSS stations to routinely generate Global Ionospheric Maps (GIMs, e.g., Schaer et al. 1998). The GIMs are provided as daily files containing global ionospheric TEC (from $-87.5^{\circ}$ to $87.5^{\circ}$ of latitude and $-180^{\circ}$ to $180^{\circ}$ of longitude) estimated each $2 \mathrm{~h}$ on a $2.5^{\circ} \times 5^{\circ}$ (latitude/longitude) grid since 1995 (Fig. 1). Nowadays, the TEC from CODE is modelled in a solar-geomagnetic reference frame using a spherical harmonics expansion up to degree and order 15 and piece-wise linear functions for representation in the time domain. Then the GIMs for a given day are the result of a 3-day combination solving for 9472 TEC parameters $(37 \mathrm{~h}$ over 3 days $\times 256$ grid points). Since 1995, the GIMs characteristics evolved with an increase of the GNSS ground network, of the number of satellites used, and of the sampling rate (Table 1). An ionospheric single thin layer hypothesis is used to express the TEC at a given altitude (typically at $400-450 \mathrm{~km}$, i.e., above the $F$ region of the ionosphere). TEC GIMs are expressed in TEC units $\left(1 \mathrm{TECu}=10^{16} \mathrm{e}^{-} / \mathrm{m}^{2}\right)$ and have a standard deviation ranging from 0.7 to $6.0 \mathrm{TECu}$ and an announced accuracy of the order of 2-8 TECu. Consequently, GIMs are a good indicator of the ionospheric activity and give the opportunity to study the global climatological behaviour of the TEC over a complete solar cycle.

In this paper, we used the GIMs from the CODE for the period 1995-2009 enclosing the entire 23rd solar cycle. Figure 2

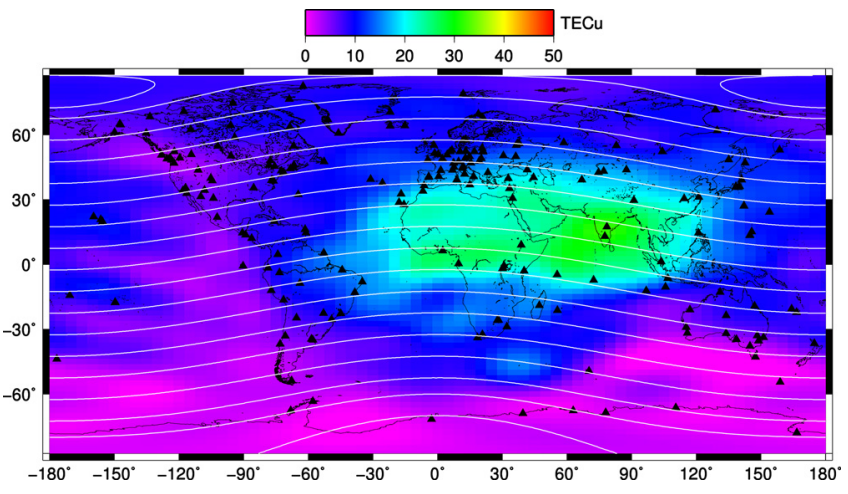

Fig. 1. Global TEC map in TECu from CODE GIMs at 12:00 UT, June 30, 2010 or Day Of Year (DOY) 181. The black triangles represent the GNSS stations (253 sites in 2010) used to model the ionosphere. White lines are the geomagnetic coordinates (dipole model) from IGRF11 (Finlay et al. 2010).

(bottom) presents the Global Daily Mean TEC (GDM-TEC) extracted from the GIMs during the entire period. GDM-TEC corresponds to the mean value from $\sim 62200$ TEC values (73 (long.) $\times 71$ (lat.) $\times 12 \mathrm{~h}$ ) of the daily GIMs files, without taking into account any specific weighting. The minimum GDMTEC is 5.4 TECu and occurs during minimal solar activity in 1996 while a maximum of $54.2 \mathrm{TECu}$ is observed during maximal activity in 2001 .

\subsection{Solar data}

\subsubsection{The daily sunspot number}

The daily Sunspot Number (SN) provides the longest record of solar activity (available since 1818). It constitutes the main reference solar index, representing the recurrence of intense magnetic loops visible on the Sun's surface. Presently, the derived International SN (Fig. 2, middle) is distributed by the Solar Influences Data Centre (SIDC, Vanlommel et al. 2005). This index is based on a statistical processing of the data from a worldwide network of 86 observatories from 29 countries (Clette et al. 2007).

\subsubsection{F10.7 solar flux}

The integrated emission from the solar disc at $2800 \mathrm{MHz}$ (10.7 cm wavelength called F10.7) is recorded routinely since 1947 (Covington 1969). The F10.7 is expressed in Solar Flux Units $\left(1 \mathrm{SFU}=10^{-22} \mathrm{Wm}^{-2} \mathrm{~Hz}^{-1}\right)$. In this study, we used the daily F10.7 estimated from the radio telescope in Penticton, British Columbia. Two sets of fluxes are used (Fig. 2, top): the F10.7 and the F10.7P. The F10.7P is the new proxy which better represents the solar EUV fluxes in a statistical sense (Liu et al. 2006; Liu \& Chen 2009). In our study, the F10.7P is computed using the mean of daily F10.7 of the day of interest and its average over the previous 81 days $(\mathrm{F} 10.7 \mathrm{~A})$ as

$$
\mathrm{F} 10.7 \mathrm{P}=\frac{\mathrm{F} 10.7+\mathrm{F} 10.7 \mathrm{~A}}{2} .
$$

The previous 81-day length was chosen to develop our climatological ionospheric model (see Sect. 2) as it ensures to stay in a forecast approach. In the following section, we investigate the linear correlations between GDM-TEC and SN, F10.7 and F10.7P solar indices for different cases and then develop our own empirical model based on these results. 
N. Bergeot et al.: Influence of space weather on TEC during the 23rd solar cycle

Table 1. Evolution of the CODE GIMs characteristics used in this study.

\begin{tabular}{|c|c|c|c|c|c|}
\hline \multicolumn{2}{|c|}{ Period } & \multirow[b]{2}{*}{ Time span (year) } & \multirow[b]{2}{*}{ VTEC maps type } & \multirow[b]{2}{*}{ Stations } & \multirow[b]{2}{*}{ Satellites } \\
\hline Beginning (YYYY-DDD) & End (YYYY-DDD) & & & & \\
\hline $1995-001$ & $1997-032$ & 2.09 & 1 map at $12: 00 \mathrm{UT}$ & $50-86$ & $\sim 24 ?$ \\
\hline $1997-033$ & 1997-054 & 0.06 & Each 2 h $(12$ maps $)+$ RMS & 72-92 & $24-25$ \\
\hline $1997-055$ & $1998-086$ & 0.09 & 1 map at $12: 00 \mathrm{UT}$ & $42-99$ & $24-27$ \\
\hline $1998-087$ & $1998-098$ & 0.03 & Each 2 h (12 maps) & $76-80$ & $27-27$ \\
\hline 1998-099 & $2009-275$ & 12.48 & Each $2 \mathrm{~h}(12$ maps $)+$ RMS & $73-261$ & $25-36$ \\
\hline
\end{tabular}

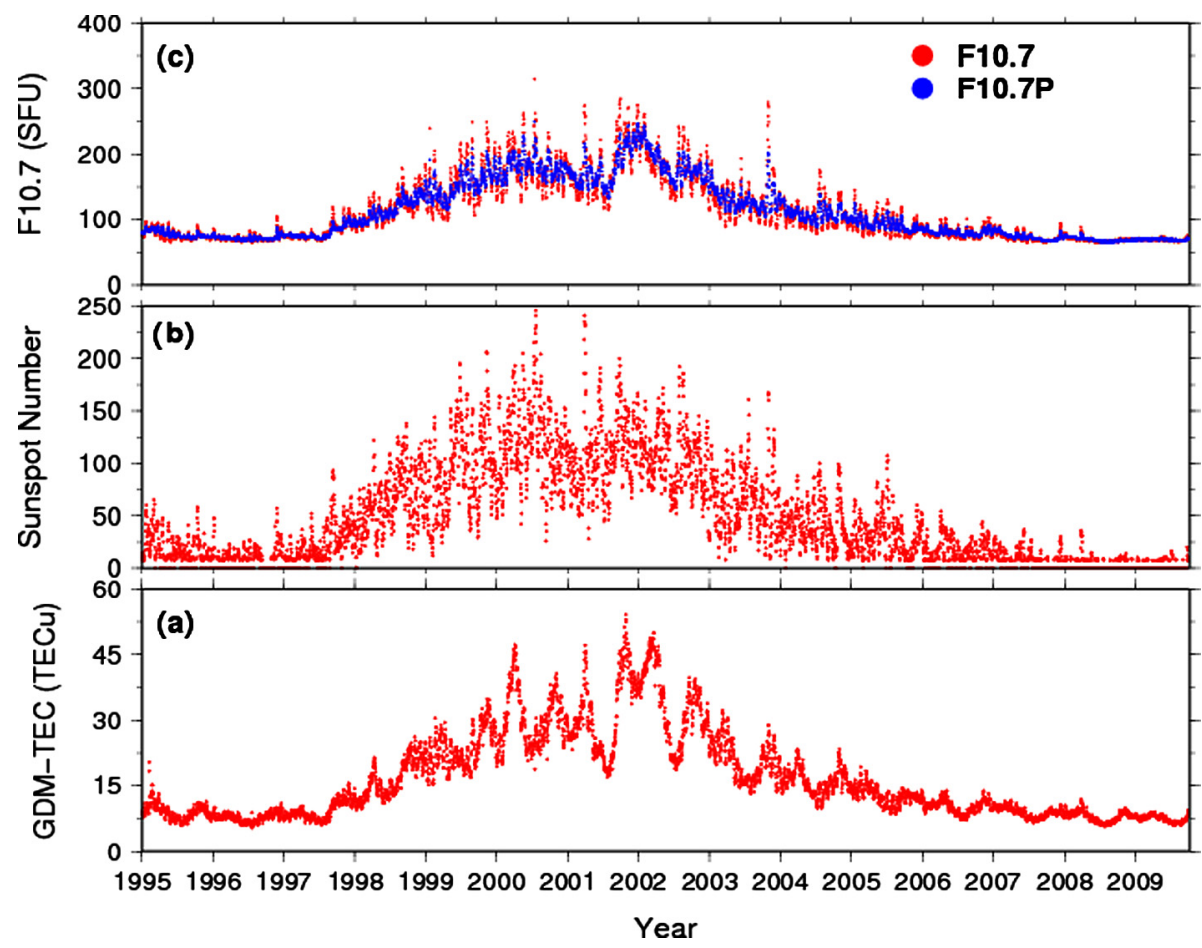

Fig. 2. Ionospheric and solar data during the 23rd solar cycle. (a) Global Daily Mean Total Electron Content (GDM-VTEC) in TECu extracted from CODE GIMs. (b) Sunspot Number as delivered by SIDC. (c) Daily F10.7 flux from Penticton radio telescope observations (red) and derived F10.7P (blue).

\section{Modelling the TEC climatological variations}

As it is well known, the solar activity variation contains a regular component with a period of about 11 years, due to the 11year sunspot cycle, a component which has a quasi-period of about a year and irregular fluctuations with periods of less than a month. The 11-year periodicity in the intensity of the solar irradiance is clearly seen in long-term ionospheric data records and is also clearly observed in the GDM-TEC time series (Fig. 2). Therefore ionospheric models (e.g., Bilitza et al. 2011; Jakowski et al. 2011) rely very often on solar indices to reproduce these long-term variations. By taking advantage of this experience, we attempt to investigate the response of the GDM-TEC to variations of the solar activity.

Figure 3 presents the scatter plots of the GDM-TEC versus the SN (Fig. 3, left), the F10.7 (Fig. 3, middle) and the F10.7P (Fig. 3, right). Inspection of these scatter plots shows a clear dispersion in GDM-TEC versus SN, reflecting a non-linear relation between the SN and GMD-TEC especially for high levels of solar activity. Consequently, a linear regression can only describe roughly the solar dependency of the GDM-TEC with respect to SN. Saturation effects at high SN are very well-known features of the dependence of $\mathrm{NmF} 2$ on $\mathrm{SN}$ (e.g., Belehaki et al. 2000). As we observed the same patterns in our results we confirm a similar response of the GDM-TEC and $\mathrm{NmF} 2$ with respect to the SN. Additionally, previous studies aiming at developing ionospheric indices showed dissatisfaction between the $\mathrm{SN}$ and the ionospheric characteristics (Mikhailov \& Mikhailov 1995a, 1995b; Secan \& Wilkinson 1997; Bilitza 2001; Tsagouri et al. 2009). A better correlation is found for F10.7 $(R=0.91)$ but the maximum linear correlation $R=0.94$ is obtained between the GDM-TEC and the F10.7P index (Fig. 3, right). Consequently, we argue that the F10.7P index has the potential to model satisfactorily at first order the ionospheric TEC variation under linear dependency. This possibility will therefore be investigated further.

Next, we investigated the latitudinal dependence of the correlation between the TEC and the F10.7P. We determined the Latitudinal Daily Mean TEC values (LDM-TEC) extracted from the GIMs. We took into account the values from a band of $20^{\circ}$ around the given latitude to determine the observed daily LDM-TEC each $10^{\circ}$ of latitude between $\mathrm{N} 80^{\circ}$ and $\mathrm{S} 80^{\circ}$. The correlations between LDM-TEC and F10.7P are then investigated in terms of different coordinate systems used to express 

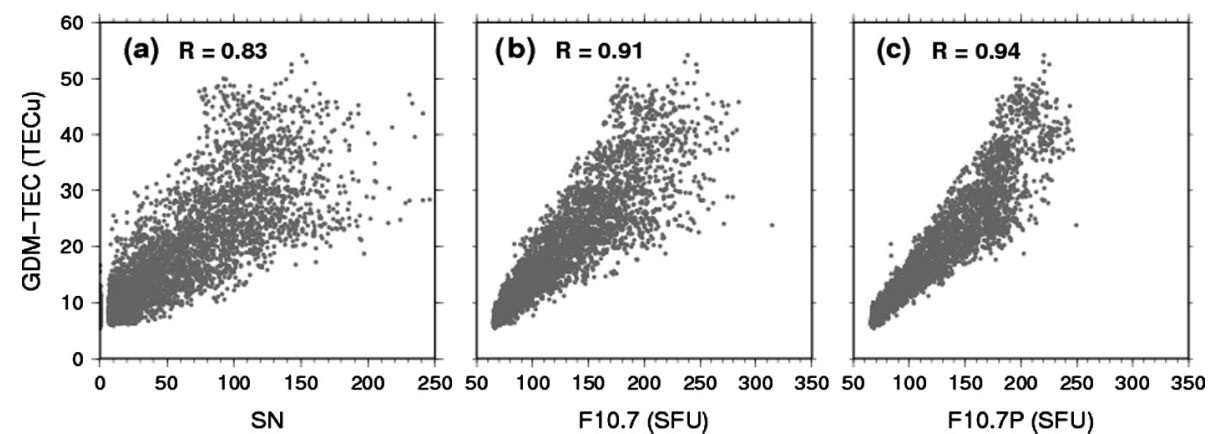

Fig. 3. Global Daily Mean Total Electron Content (GDM-TEC) versus the daily solar indices during the 23rd solar cycle. The figures show the typical data sets generally used to estimate the linear correlation coefficient between GDM-TEC and (a) daily Sunspot Number, (b) daily F10.7 and (c) F10.7P. Also given is the linear correlation coefficients $R$ between the GMD-TEC and solar indices.

the ionospheric LDM-TEC, and in terms of different Earth's seasons and different phases of solar cycle.

As the plasma transport is organized mainly in geomagnetic coordinates (e.g., Klobuchar 1987), the relation between the LDM-TEC and the F10.7P is plotted as a function of both the geomagnetic and geographic latitudes. The geomagnetic coordinates were obtained using the IGRF11 model (Finlay et al. 2010) and a dipole approximation of the geomagnetic field. One transformation per year was performed between the geographic and geomagnetic coordinates as the variations in the geomagnetic field are negligible for shorter time scales. The results (Fig. 4) show that the linear correlation between the LDM-TEC and the F10.7P does not significantly change depending on the coordinate system, except for latitudes close to $30^{\circ} \mathrm{S}$. At this latitude, the South Atlantic Magnetic Anomaly leads to complex phenomena in the equatorial ionospheric electrodynamics as well as unusual effects on the $\mathrm{E}$ and $\mathrm{F}$ layer densities (e.g., Abdu et al. 2005) even under magnetically quiet periods. We will therefore use the LDM-TEC expressed in geomagnetic coordinates for our study.

The maximum linear correlation between LDM-TEC/ F10.7P $(R=0.93)$ is observed at latitudes of $\mathrm{N} 10^{\circ}$ and $\mathrm{N} 20^{\circ}$. The high linear correlation at these latitudes may be considered as evidence for no saturation effects. This is in contradiction with previous work which showed saturation and/or amplification effects for both NmF2 and TEC versus F10.7 and F10.7P (e.g., Liu et al. 2006; Liu \& Chen 2009). In fact, the decrease of linear relation between LDM-TEC and F10.7P at high latitudes can be interpreted as an increase of non-linear effects, which will be identified later as annual and semi-annual dependencies. Additionally, a dichotomy can be identified with a lower correlation in Southern hemisphere $(R=0.84 \pm 0.06)$ than in the Northern hemisphere $(R=0.90 \pm 0.04)$, which might be due to the effect of thermospheric meridional winds which are stronger in the Northern than in the Southern hemisphere. This effect can lead to significant differences in the NmF2 seasonal anomaly with respect to the hemisphere as already shown from long-term ionosonde data (Rishbeth 1998; Ma et al. 2009).

To study the TEC response to the relative position and orientation of the Earth/Sun system, the correlations between LDM-TEC and F10.7P are independently investigated for spring, summer, autumn and winter seasons of the Northern hemisphere (Fig. 5). The maximum linear correlation $(R=0.97)$ is close to $\mathrm{S} 30^{\circ}$ latitude during the winter while the minimum $(R=0.76)$ occurs during summer period close to the South Pole. However, there is no clear pattern in the different curves except for the hemispheric dichotomy already discussed previously.

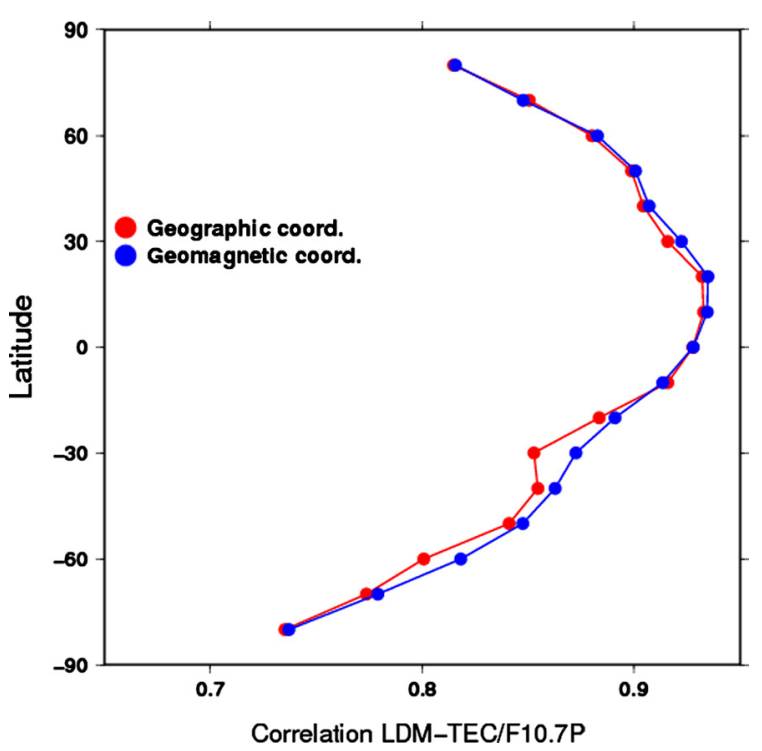

Fig. 4. Latitudinal dependency of the LDM-TEC/F10.7P linear correlation depending on the coordinate system used to express the LDM-TEC.

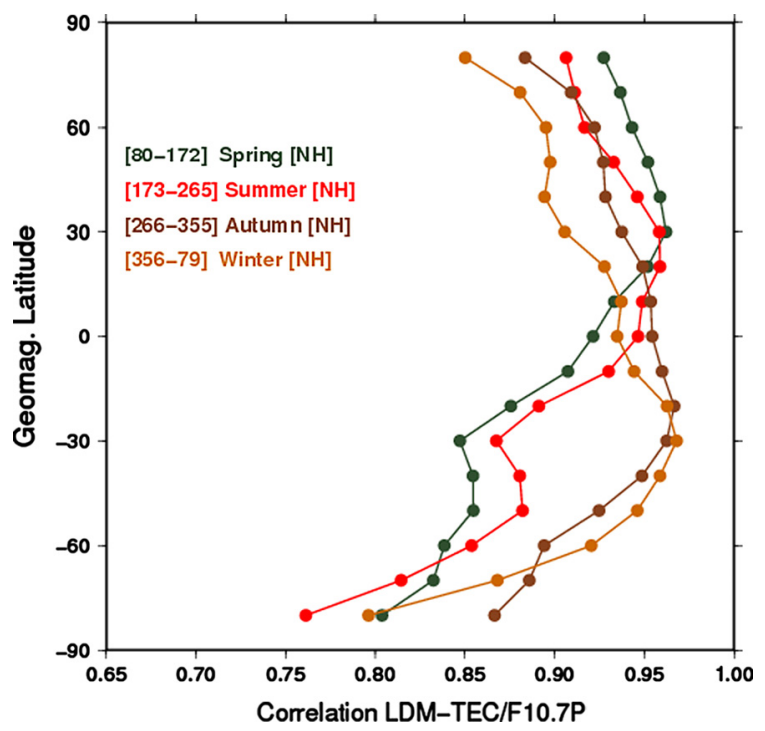

Fig. 5. Latitudinal dependency of the LDM-TEC/F10.7P linear correlation as a function of the seasons in the Northern hemisphere. The numbers enclosed in brackets correspond to the time period expressed as the day of year used for each season. 
N. Bergeot et al.: Influence of space weather on TEC during the 23rd solar cycle

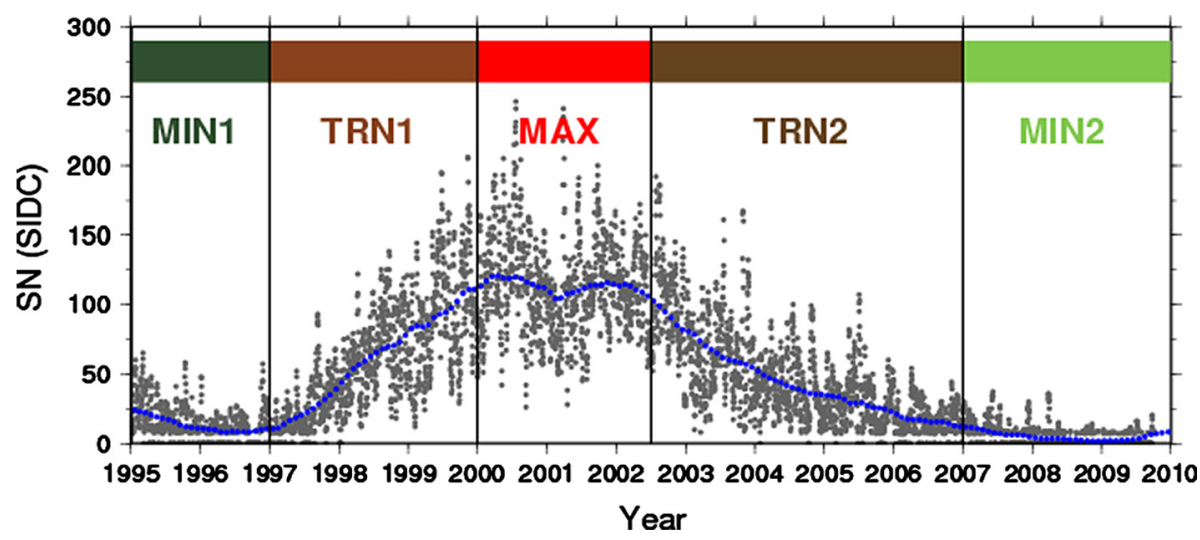

Fig. 6. Sunspot number (SN) delivered by the SIDC. Grey dots: daily SN; blue dots: smoothed monthly SN. The coloured rectangles on the top correspond to the different activity phases of the Sun considered: MIN1 and MIN2 for the two minimum activity phases; TRN1 and TRN2 for the two transition activity phases; MAX for the maximum activity phase.

The latitudinal LDM-TEC and the F10.7P are now divided into solar activity phases (Fig. 6) characterized by the smoothed monthly SN (Clette et al. 2007) with: two solar minimum activity phases (1995-1997 and 2007-2009), two solar transition activity phases (1997-2000 and 2002-2007) and one solar maximum activity phase (2000-2002). Figure 7 shows that the estimated linear correlations are clearly similar for the two transitions as well as for the two minimum solar activity phases, even if they are estimated completely independently. Linear correlations are larger during solar transition activity phases $(R=0.77 \pm 0.10)$ and decrease during maximum $(R=0.57 \pm 0.07)$ and minimum $(R=0.34 \pm 0.21)$ phases. Moreover, a complete linear de-correlation is observed at $\mathrm{N} 50^{\circ}$ during solar minimums. The hemispheric dichotomy is predominant during the minimum solar phases and is coherent during the two solar minimums. Consequently, different patterns in the ionospheric TEC with respect to the solar activity phases are to be taken into account. Afraimovich et al. (2008) already mentioned a different shape of the temporal evolution of the global TEC with respect to the solar activity phases. The authors interpreted the different patterns of the global TEC by the variation of the number and type of active regions in the Sun's atmosphere. Our results confirm that it is mandatory to consider different ionization responses with respect to solar activity phases. This is particularly important when the solar indices are used to model the ionospheric TEC.

Considering all these results we developed our model to predict the LDM-TEC from the F10.7P data only, using a least-squares approach. To minimize the differences between the modelled and observed LDM-TEC, we considered (1) a combination of linear, annual and semi-annual terms and (2) a discretization with respect to the solar cycle phases as defined previously. We obtained the equation below and used it to estimate the LDM-TEC from the F10.7P for a given day $(t)$, at a given geomagnetic latitude $(\varphi)$ and solar cycle phase (sc):

$$
\begin{aligned}
\mathrm{LDM} & -\mathrm{TEC}(t, \varphi)=\mathrm{F} 10.7 \mathrm{P}(t) \times \boldsymbol{A}(\varphi, \mathrm{sc})+\boldsymbol{B}(\varphi, \mathrm{sc}) \\
& +\mathrm{F} 10.7 \mathrm{P}(t) \times[\boldsymbol{C}(\varphi, \mathrm{sc}) \times \sin (2 \pi t)+\boldsymbol{D}(\varphi, \mathrm{sc}) \times \cos (2 \pi t)] \\
& +\mathrm{F} 10.7 \mathrm{P}(t) \times[\boldsymbol{E}(\varphi, \mathrm{sc}) \times \sin (4 \pi t)+\boldsymbol{F}(\varphi, \mathrm{sc}) \times \cos (4 \pi t)]
\end{aligned}
$$

with $[A / B]$ the coefficients for the linear term, $[C / D]$ for the annual term and $[E / F]$ for the semi-annual term. The linear component reflects the high linear correlation between the F10.7P and LDM-TEC studied previously while the annual and semi-annual components reflect the variations in the

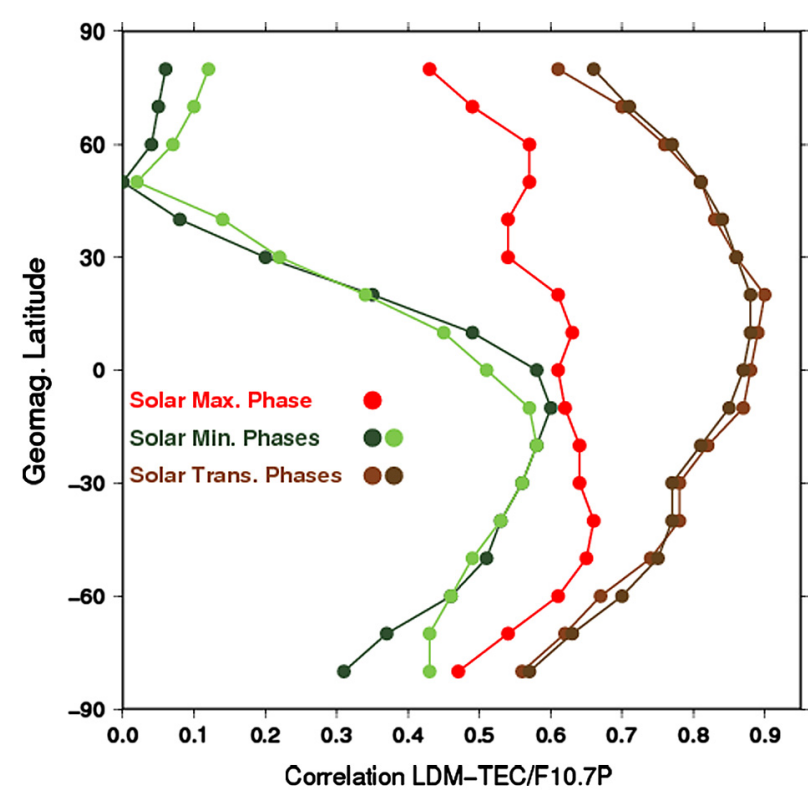

Fig. 7. Latitudinal dependency of the LDM-TEC/F10.7P linear correlation with respect to the solar cycle phases. The colours correspond of the different solar activity phases defined in Figure 6.

Sun-Earth distance (and solar zenith angle) and the changes in the neutral composition (Zhang et al. 2005).

From the least-squares analysis, we determined 510 coefficients, corresponding to 6 coefficients for each of the 5 solar cycle phases and each of the 17 latitude levels. The obtained 510 coefficients (Fig. 8) present, at first order, the same magnitude for the different phases of the solar cycle. Linear coefficient $A$ is quasi-constant at a given latitude during the solar cycle, while $B$ shows an important disparity during the maximum solar activity. The hemispheric dichotomy is clear on the two annual terms $(C$ and $D)$ with a significant increase in the coefficients at high latitudes compared to low and equatorial latitudes. This confirms that the decrease of linear correlation at high latitudes between LDM-TEC and F10.7P (see Sect. 2 and Fig. 4) is mainly due to the predominance of an annual (nonlinear) term. The semi-annual terms $(E$ and $F)$ affect mainly the LDM-TEC at low latitudes. This is due the large variations of the ratio $[\mathrm{O}] /\left[\mathrm{N}_{2}\right]$ at low latitude between summer and winter (Bhuyan \& Borah 2007). Contrary, the variation of this ratio is less important at high latitudes. As the free electrons 

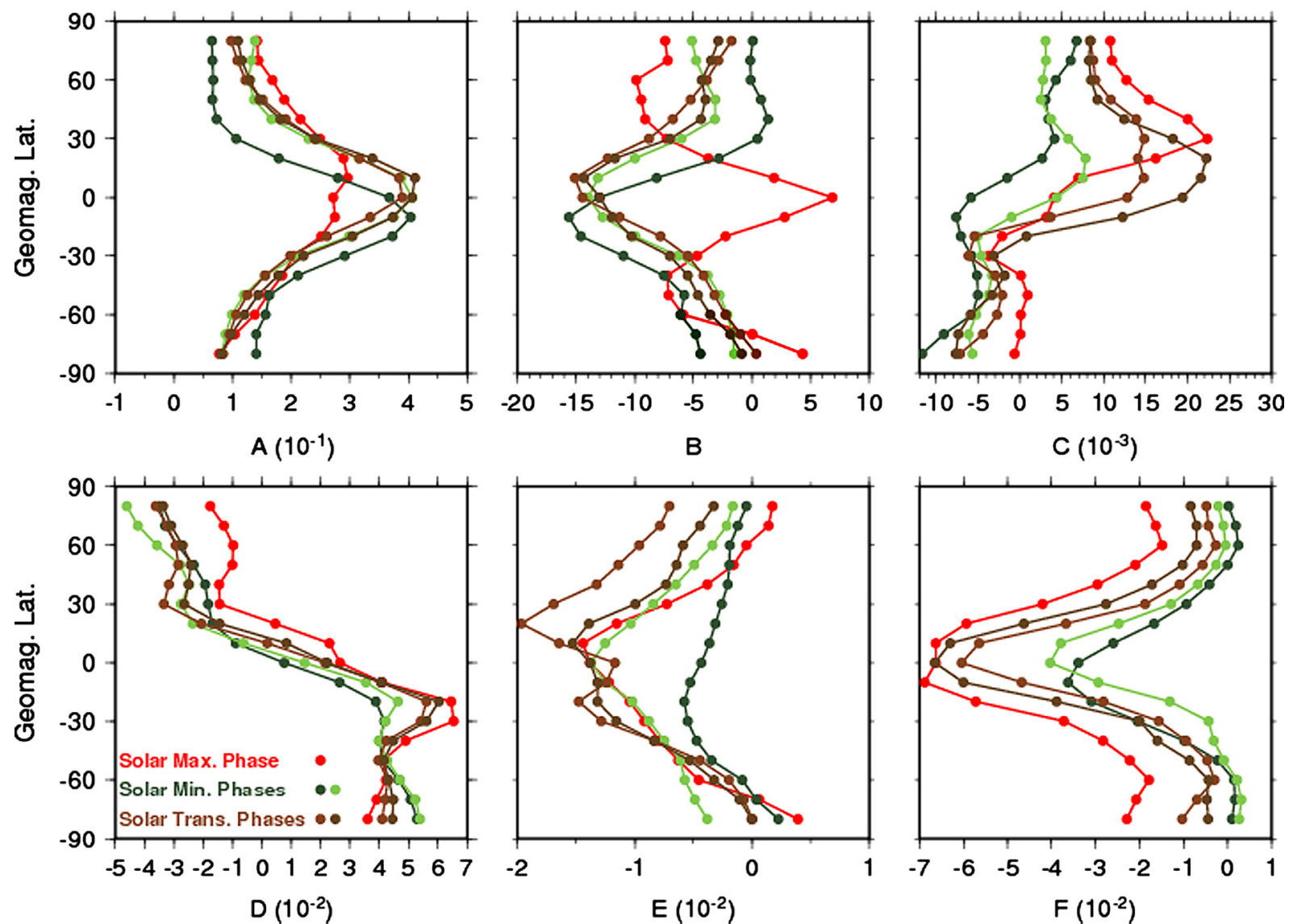

Fig. 8. Linear (A, B), annual (C, D) and semi-annual (E, F) coefficients used to estimate the daily mean LDM-TEC from the F10.7P. Each picture shows the estimated coefficient with respect to the geomagnetic latitude and the different solar cycle phases.

production/recombination is related to this atomic/molecule ratio, the low latitudes are more sensitive to semi-annual variations than the high latitudes. Consequently, our model of LMDTEC reconstruction from $\mathrm{F} 10.7 \mathrm{P}$ reflects the general variations of the ionospheric TEC: predominance of (1) the annual term at high latitudes due to the solar zenith angle and (2) the semiannual term at low latitudes where the change of the ratio $[\mathrm{O}] /\left[\mathrm{N}_{2}\right]$ plays an important role.

\section{Test of the climatological model}

The results of the modelled LDM-TEC are presented in Figure 9 for three different latitudes and show a good agreement with the observations. For the entire period, the residuals are lower than $3 \mathrm{TECu}$ for $87 \%$ of the days at high latitudes, $85 \%$ at mid-latitudes and $77 \%$ at equatorial latitudes. The residuals larger than $3 \mathrm{TECu}$ occurred during the solar maximum and transition phases (50\% and $47 \%$ respectively). Residuals are larger during the solar maximum $(4.3 \pm 3.3 \mathrm{TECu})$ compared with the other phases $(1.7 \pm 2.4$ and $0.7 \pm 1.1 \mathrm{TECu}$ for transition and minimum phases respectively). The standard deviation of the differences between the modelled and observed LMD-TEC (Fig. 10) is lower than $3.4 \mathrm{TECu}$ and is maximal at the geomagnetic equator. Moreover, the mean standard deviation $(2.5 \pm 0.4$ TECu) is significantly lower compared with the case where we do not consider different phases in the solar cycle $(2.9 \pm 0.4 \mathrm{TECu})$. This comforts us in our strategy which consists in discretizing the modelling with respect to the solar cycle phases.

We now investigated the differences (differences between observed and modelled LMD-TEC) and the relative differences (differences scaled by the observed LDM-TEC) during the entire period 1995-2009. The median difference is $1.9 \pm 0.9$ $\mathrm{TECu}$ (Fig. 11, bottom) tending to be the greatest during maximum solar activity (in 2000) and decreasing as the latitude increases. The median relative difference (Fig. 11, top) is $7.3 \pm 2.0 \%$ and is free of solar cycle dependence while it increases with latitude. The scatter plot between the observed and modelled values (Fig. 12) shows that the residuals between observed and modelled LDM-TEC are negligible with a standard deviation of $2.6 \mathrm{TECu}$. The linear correlation between the model and the observations is $R=0.98$, verifying that the model is efficient and well adapted to estimate LDM-TEC at latitudes between $\mathrm{S} 80^{\circ}$ and $\mathrm{N} 80^{\circ}$.

For the entire period and for all latitudes, 97 outliers $(\sim 0.1 \%$ of the data) were detected, considering as outliers the residuals between the observed and modelled LDM-TEC greater than 15 TECu (Fig. 12, red dots). Only $13 \%$ of these outliers are due to GIMs problems detected visually (e.g., abnormal high TEC values at polar latitudes during the entire day) or to unidentified problems (no problem in the GIMs and no evident disturbed periods). The remaining outliers $(87 \%)$ are concordant with the occurrence of 69 intense geomagnetic storm events. This indicates that the large deviations between modelled and observed LDM-TEC are mainly attributed to enhancements in geomagnetic activity.

\section{Effect of geomagnetic storms on the TEC}

To analyse the effect of geomagnetic storms on LDM-TEC time disturbances, we investigated the differences between our 


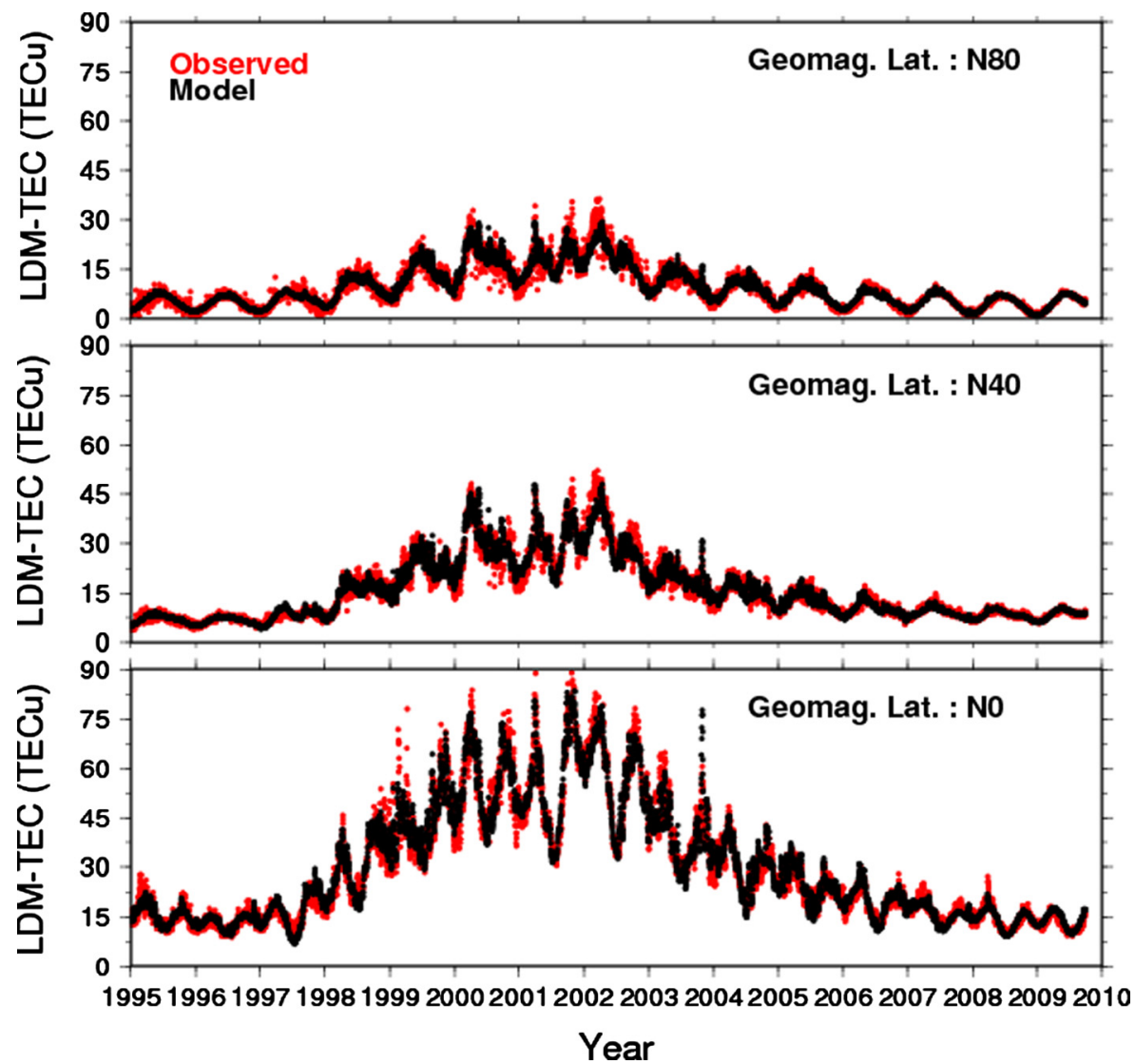

Fig. 9. Modelled (in black) and observed (in red) LDM-TEC for different geomagnetic latitudes. Bottom: geomagnetic equator. Middle: midlatitude region. Top: polar region.

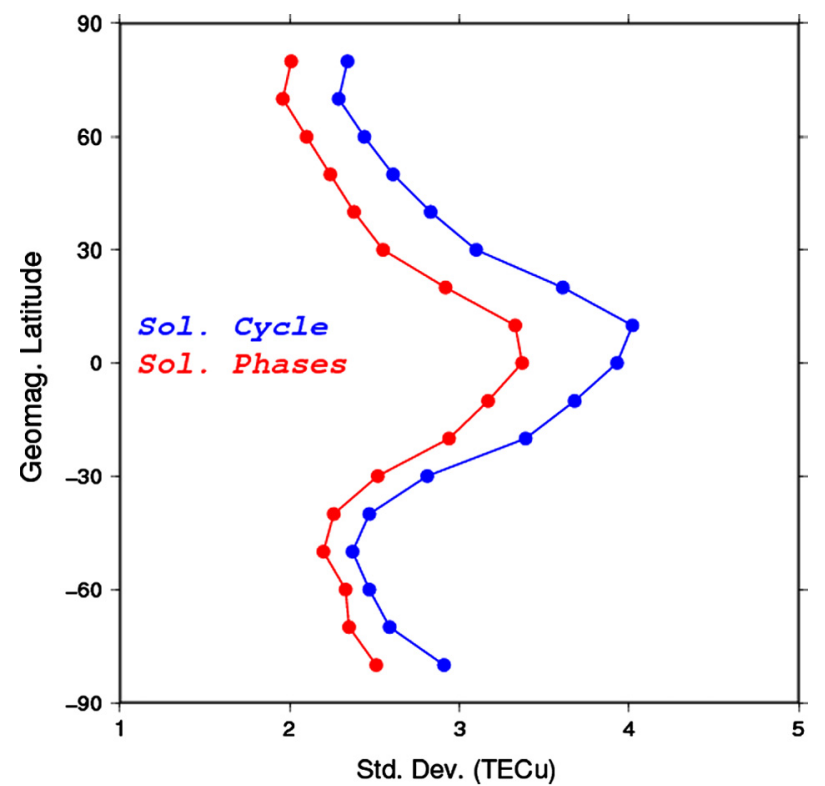

Fig. 10. Standard deviation $(1 \sigma)$ of the differences between the modelled and the observed LDM-TEC with respect to the geomagnetic latitude. Blue: when performing a least-squares adjustment without considering any solar cycle phase. Red: when the leastsquares adjustment is performed for the different solar cycle phases.

climatological LDM-TEC model and the observations for the 69 storm onsets identified (Tsagouri \& Belehaki 2008) during the period 1998-2005 (Fig. 13). The onsets were determined from the Interplanetary Magnetic Field (IMF) measurements provided by the NASA Advanced Composition Explorer (ACE) spacecraft situated at the Lagrangian point L1 (i.e., situated at $\sim 1.5 \times 10^{6} \mathrm{~km}$ from the Earth). We stacked and estimated the mean values of the differences between the modelled and observed LDM-TEC (Fig. 14, top) and the mean relative differences (i.e., scaled by the observed values, Fig. 14, bottom) for the 20 days around each storm onset. Figure 14 demonstrates that the storms significantly affect the LDMTEC mainly at high latitudes, with a loss of ionization with respect to the climatological model. The peak of the ionization depletion is detected one day after the onset. The mean difference between the observed and modelled LDM-TEC at the peak is $-3.2 \pm 1.5 \mathrm{TECu}$ and becomes negligible $3-4$ days after the onset. The relative differences are of the order of $-19.6 \pm 15.0 \%$ one day after the onset and normal values are observed again 3-4 days after the onset. In general, the LDM-TEC storm-time response is characterized by significant (about $20 \%$ on average) reductions with respect to the climatological variation observed globally with a peak within the first day after the storm onset. The above pattern seems to follow the expected scenario of the effect of a geomagnetic storm on the ionosphere. Based on previous theories, the global scale feature of the ionospheric perturbation on storm-time response is the long-lived negative storm effect (Prolss 1993; Fuller-Rowell et al. 1994; Tsagouri et al. 2000). However, a slight increase in the LDM-TEC with respect to the model is observed at low latitudes. This can be explained by positive storm effects at mid and low latitudes due to a response to neutral wind activity and/or electric field penetration.

The ionospheric responses to geomagnetic storm effects were modelled for ionospheric forecasting purposes (Tsagouri 

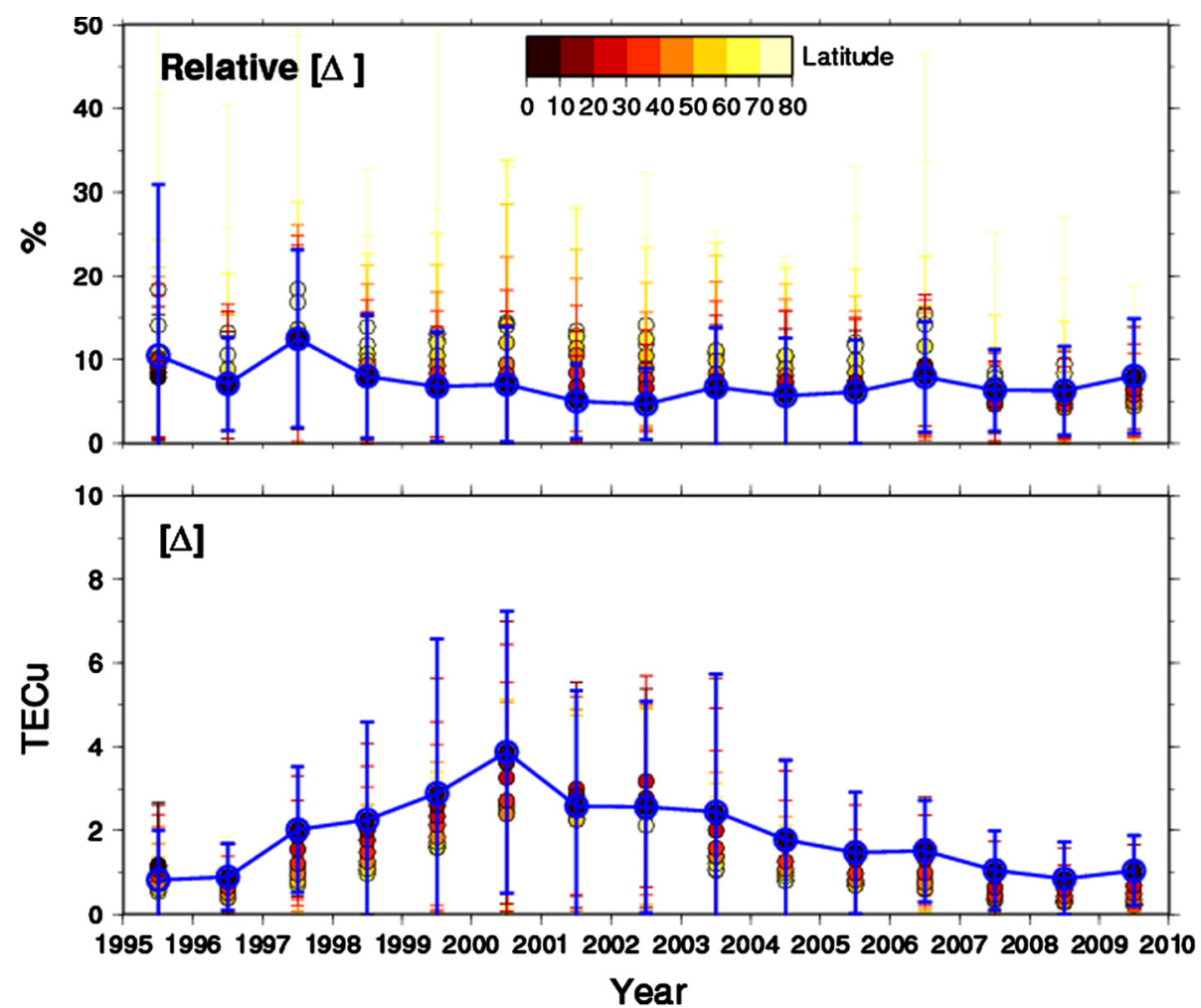

Fig. 11. Yearly errors (bottom) and relative errors (top) of the climatological LDM-TEC model with respect to the latitude (white to black). Also represented are the yearly mean errors for the entire latitudes (blue).

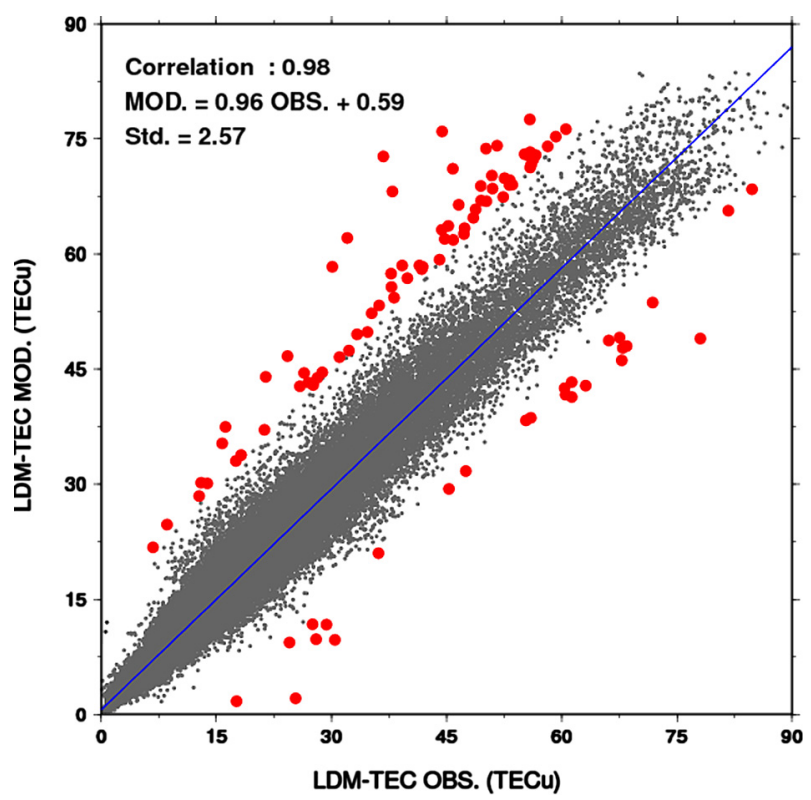

Fig. 12. Scatter plot of the modelled and observed LDM-TEC. Red points: differences greater than or equal to $15 \mathrm{TECu}$ between observed and modelled LDM-TEC.

\& Belehaki 2008; Tsagouri et al. 2009). According to these results, the geomagnetic storm onset follows the storm onset at L1 point with a delay that ranges from 2 to $12 \mathrm{~h}$, while the ionospheric disturbances may last from 10 to $40 \mathrm{~h}$ depending on the local time of the observation point at the storm onset. Of course, any new intensification of the geomagnetic activity (e.g., successive storm events or storm events with multiple onsets), results in new generated ionospheric disturbances. This

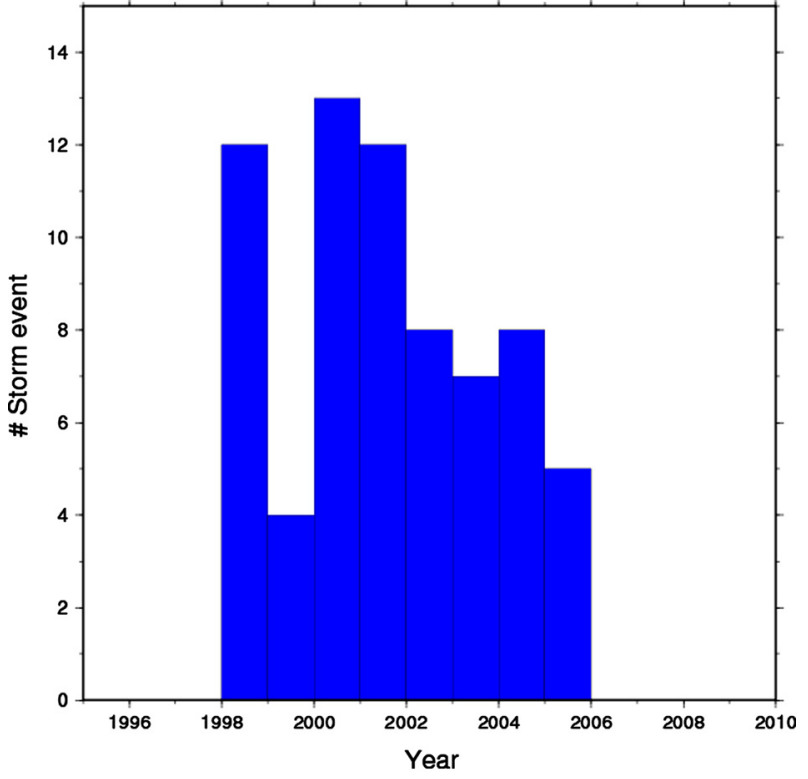

Fig. 13. Number of intense geomagnetic storms for the period 1998-2005 based on Interplanetary Magnetic Field data collected from ACE satellite (Tsagouri \& Belehaki 2008).

can lead to an extension of the disturbed period persistent up to 3 or 4 days or even more (Tsagouri et al. 2000). One other possibility for explaining the long-time effect of the storm on the TEC depletion detected at mid-latitudes is given by Mendillo (2006). In this paper, the author interpreted the persisting depletion in TEC a few days after the onset by the contraction of the plasmasphere. This contraction implies disturbances in the thermosphere circulation and a chemical loss in the ionosphere and, 


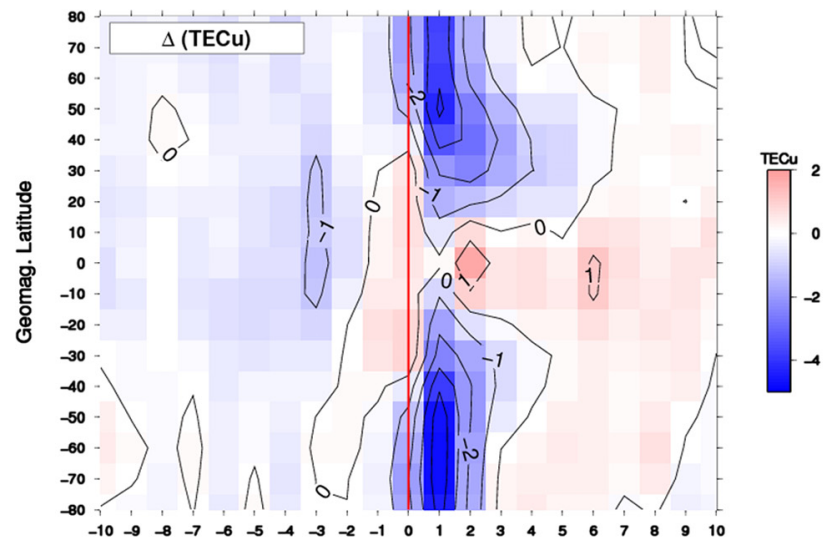

Day wrt storm onset

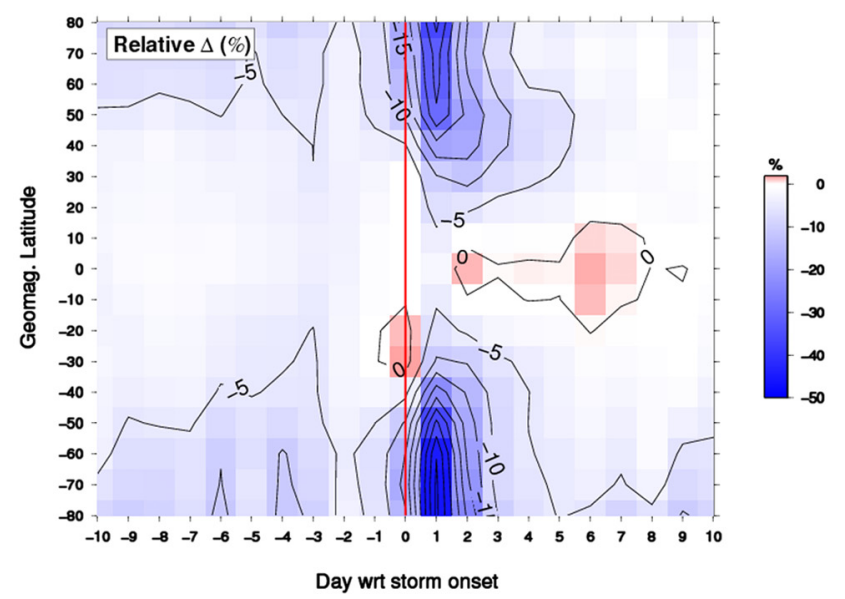

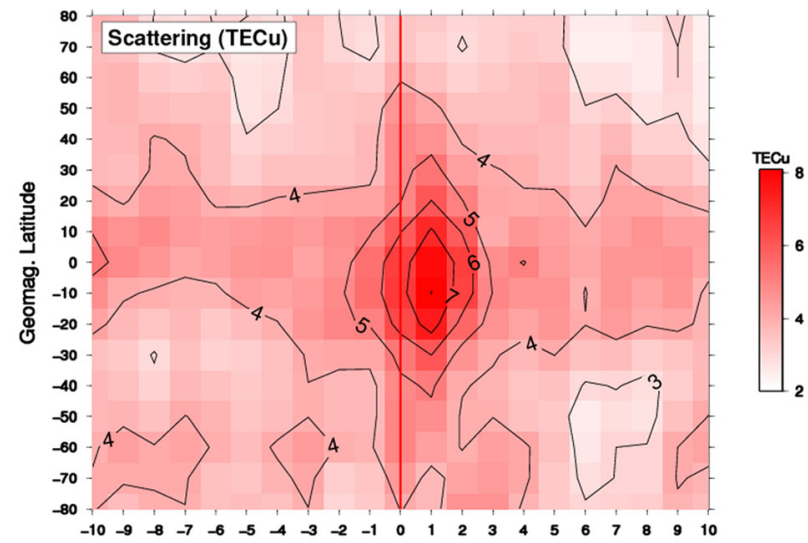

Day wrt storm onset

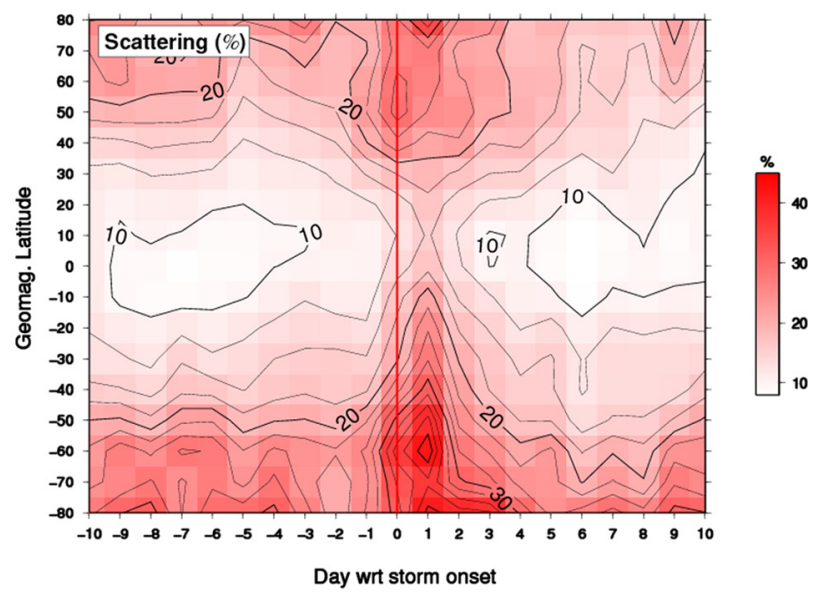

Fig. 14. Mean effect of geomagnetic storms on LDM-TEC for a period of 20 days around the onset. Top left: mean differences $(\Delta)$ between the modelled and observed LDM-TEC in TECu. Top right: scattering of the differences. Bottom left: mean relative differences (scaled by the observed) in percentage. Bottom right: scattering of the relative differences. The red line is day of the detected onset of the storms.

consequently, a decrease of TEC. To determine the best scenario and draw conclusions on a physical/chemical explanation of our observations, an accurate knowledge of the plasmasphere-ionosphere system is now of first importance especially during geomagnetic storms.

\section{Conclusions}

We developed a new empirical model to predict the climatological behaviour of the ionosphere at a global scale $\left(\mathrm{S} 80^{\circ}-\mathrm{N} 80^{\circ}\right)$. Our model allows the estimation of the daily mean TEC at a given latitude from only the F10.7P parameter as input. To develop our model we needed to take in consideration different coefficients with respect to the solar cycle phases. The mean standard deviation of this new model is $2.5 \pm 0.4 \mathrm{TECu}$ for all latitudes over the entire period (1995-2009), better than when no discretization between solar cycle phases is taken into consideration. Consequently, empirical models developed to predict the ionospheric TEC from solar indices should take into account for different behaviours with respect to solar activity phases. The main outliers between the observed and modelled TEC correspond to geomagnetic storm events for the period 1998-2005. Geomagnetic storms affect mainly the daily TEC in Polar Regions with a maximum decrease of ionization one day after the onset $(-3.2 \pm 1.5 \mathrm{TECu}$ in absolute and $-19.6 \pm 15.0 \%$ in relative differences) returning to pre-storm conditions values 3-4 days after. In the future, a better understanding of the topside ionosphere and of the plasmasphere-ionosphere coupling during geomagnetic storm is essential to draw a general physical/chemical schema of the TEC depletion persisting for a few days after the storm onset.

Acknowledgements. This work has been supported by the Solar and Terrestrial Centre of Excellence (STCE, http://www.stce.be/) and by the COST ES 0803 "Developing Space Weather Products and Services in Europe" action. The authors also acknowledge the CODE IGS Analysis Centre for their GIM maps (ftp://ftp.unibe.ch/ aiub/CODE), the SIDC for the sunspot number time-series (http:// sidc.oma.be/sunspot-data/) as well as NGDC NOAA for the F10.7 index data (ftp://ftp.ngdc.noaa.gov/STP/SOLAR_DATA/).

\section{References}

Abdu, M.A., I.S. Batista, A.J. Carrasco, and C.G.M. Brum, South Atlantic magnetic anomaly ionization: a review and a new focus on electrodynamic effects in the equatorial ionosphere, J. Atmos. Sol. Terr. Phys., 67 (17-18), 1643-1657, DOI: 10.1016/j.jastp. 2005.01.014, 2005.

Afraimovich, E.L., E.I. Astafyeva, A.V. Oinats, Y.V. Yasukevich, and I.V. Zhivetiev, Global electron content: a new conception to track solar activity, Ann. Geophys., 26, 335-344, 2008.

Belehaki, A., G. Moraitis, and I. Tsagouri, On the derivation of an hourly local index to define the normal ionosphere, Ann. Geophys., 43 (1), 189-230, DOI: 10.4401/ag-3629, 2000.

Bhuyan, P.K., and R.R. Borah, TEC derived from GPS network in India and comparison with the IRI, Adv. Space Res., 39 (5), 830840, 2007. 
Bilitza, D., International Reference Ionosphere 2000, Radio Sci., 36 (2), 261-275, DOI: 10.1029/2000RS002432, 2001.

Bilitza, D., B.W. Reinisch, S.M. Radicella, S. Pulinets, T. Gulyaeva, and L. Triskova, Improvements of the International Reference Ionosphere model for the topside electron density profile, Radio Sci., 41 (5), RS5S15, DOI: 10.1029/2005RS003370, 2006.

Bilitza, D., L.-A. McKinnell, B. Reinisch, and T. Fuller-Rowell, The International Reference Ionosphere (IRI) today and in the future, $J$. Geod., 85 (12), 909-920, DOI: 10.1007/s00190-010-0427-x, 2011.

Clette, F., D. Berghmans, P. Vanlommel, R. Van der Linden, A. Koeckelenbergh, and L. Wauters, From the Wolf number to the International Sunspot Index: 25 years of SIDC, Adv. Space Res., 40 (7), 919-928, ISSN: 0273-1177, DOI: 10.1016/j.asr.2006.12.045, 2007.

Covington, A.E., Solar Radio Emission at $10.7 \mathrm{~cm}, 1947-1968, J . R$. Astron. Soc. Can., 63, 125-132, 1969.

Finlay, C.C., S. Maus, C.D. Beggan, T.N. Bondar, and A. Chambodut, et al., International geomagnetic reference field: the eleventh generation, Geophys. J. Int., 183 (3), 1216-1230, DOI: 10.1111/j.1365-246X.2010.04804.x, 2010.

Fuller-Rowell, T.J., M.V. Codrescu, R.J. Moffett, and S. Quegan, Response of the thermosphere and ionosphere to geomagnetic storms, J. Geophys. Res., 99 (A3), 3893-3914, ISSN: 0148-0227, DOI: 10.1029/93JA02015, 1994.

Iwamoto, I., H. Katoh, T. Maruyama, H. Minakoshi, S. Watari, and $\mathrm{K}$. Igarashi, Latitudinal variations of solar flux dependence in the topside plasma density: comparison between IRI model and observations, Adv. Space Res., 29 (6), 877-882, ISSN: 02731177, DOI: 10.1016/S0273-1177(02)00054-6, 2002.

Jakowski, N., M.M. Hoque, and C. Mayer, A new global TEC model for estimating transionospheric radio wave propagation errors, J. Geod., 85 (12), 965-974, ISSN: 0949-7714, DOI: 10.1007/s00190-011-0455-1, 2011.

Kenpankho, P., K. Watthanasangmechai, P. Supnithi, T. Tsugawa, and T. Maruyama, Comparison of GPS TEC measurements with IRI TEC prediction at the equatorial latitude station, Chumphon, Thailand, Earth Planets Space, 63 (4), 365-370, 2011.

Klobuchar, J., Ionospheric time-delay algorithms for single-frequency GPS users, IEEE Trans. Aerosp. Electron. Syst., 23 (3), 325-331, 1987.

Liu, L., W. Wan, B. Ning, O.M. Pirog, and V.I. Kurkin, Solar activity variations of the ionospheric peak electron density, J. Geophys. Res., 111 (8), A08304, DOI: 10.1029/2006JA011598, 2006.

Liu, L., and Y. Chen, Statistical analysis of solar activity variations of total electron content derived at Jet Propulsion Laboratory from GPS observations, J. Geophys. Res., 114, A10311, DOI: 10.1029/2009JA014533, 2009.

Liu, L., W. Wan, B. Ning, and M.-L. Zhang, Climatology of the mean total electron content derived from GPS global ionospheric maps, J. Geophys. Res., 114, A06308, DOI: 10.1029/2009JA014244, 2009.
Ma, R., J. Xu, W. Wang, and W. Yuan, Seasonal and latitudinal differences of the saturation effect between ionospheric $\mathrm{NmF} 2$ and solar activity indices, J. Geophys. Res., 114, A10303, DOI: 10.1029/2009JA014353, 2009.

Mendillo, M., Storms in the ionosphere: patterns and processes for total electron content, Rev. Geophys., 44, RG4001, DOI: 10.1029/2005RG000193, 2006.

Mikhailov, A.V., and V.V. Mikhailov, Solar cycle variations of annual mean noon foF2, Adv. Space Res., 15 (2), 79-82, 1995a.

Mikhailov, A.V., and V.V. Mikhailov, A new ionospheric index MF2, Adv. Space Res., 15 (2), 93-97, 1995b.

Orús, R., M. Hernández-Pajares, J.M. Juan, J. Sanz, and M. GarcíaFernández, Performance of different TEC models to provide GPS ionospheric corrections, J. Atmos. Sol. Terr. Phys., 64 (18), 2055 2062, ISSN: 1364-6826, DOI: 10.1016/S1364-6826(02)00224-9, 2002.

Prolss, G.W., On explaining the local time variation of ionospheric storm effects, Ann. Geophys., 11, 1-9, 1993.

Rishbeth, H., How the thermospheric circulation affects the ionospheric F2-layer, J. Atmos. Sol. Terr. Phys., 60 (14), 1385-1402, ISSN: 1364-6826, DOI: 10.1016/S1364-6826(98)00062-5, 1998.

Schaer, S., W. Gurtner, and J. Feltens, IONEX: The IONosphere Map EXchange Format Version 1. Proceedings of the 1988 IGS Analysis Centers Workshop, ESOC, Darmstadt, Germany, February 9-11, pp. 233-247, 1998.

Secan, J.-A., and P.J. Wilkinson, Statistical studies of an effective sunspot number, Radio Sci., 32, 1717-1724, DOI: 10.1029/97RS01350, 1997.

Tsagouri, I., A. Belehaki, G. Moraitis, and H. Mavromichalaki, Positive and negative ionospheric disturbances at middle latitudes during geomagnetic storms, Geophys. Res. Lett., 27 (21), 3579 3582, ISSN: 0094-8276, DOI: 10.1029/2000GL003743, 2000.

Tsagouri, I., and A. Belehaki, An upgrade of the solar-wind-driven empirical model for the middle latitude ionospheric storm-time response, J. Atmos. Sol. Terr. Phys., 70 (16), 2061-2076, ISSN: 1364-6826, DOI: 10.1016/j.jastp. 2008.09.010, 2008.

Tsagouri, I., K. Koutroumbas, and A. Belehaki, Ionospheric foF2 forecast over Europe based on an autoregressive modeling technique driven by solar wind parameters, Radio Sci., 44, RS0A35, DOI: 10.1029/2008RS004112, 2009.

Vanlommel, P., P. Cugnon, R. Van Der Linden, D. Berghmans, and F. Clette, The SIDC: World Data Center for the Sunspot Index, Solar Physics, 2004-10-01, Springer Netherlands, 0038-0938, Phys. Astron., 224 (1), 113-120, DOI: 10.1007/s11207-005-6504-2, 2005.

Zhang, S.-R., J.M. Holt, A.P. van Eyken, M. McCready, C. AmoryMazaudier, S. Fukao, and M. Sulzer, Ionospheric local model and climatology from long-term databases of multiple incoherent scatter radars, Geophys. Res. Lett., 32, L20102, DOI: 10.1029/2005GL023603, 2005.

Cite this article as: Bergeot N, Tsagouri I, Bruyninx C, Legrand J, Chevalier J, et al.: The influence of space weather on ionospheric total electron content during the 23rd solar cycle. J. Space Weather Space Clim., 2013, 3, A25. 